\title{
Microwave-Plasma Synthesis of Nano-sized Silicon Carbide at Atmospheric Pressure
}

\author{
JH van Laar ${ }^{*}$, JFM Slabber $^{1}$, JP Meyer $^{1}$, IJ vd Walt $^{2}$, GJ Puts ${ }^{3}$, PL Crouse $^{3}$ \\ ${ }^{I}$ Thermoflow Group, Department of Mechanical Engineering, Faculty of Engineering, Built Environment and \\ Information Technology, University of Pretoria, Pretoria, South Africa \\ ${ }^{2}$ Applied Chemistry Division, South African Nuclear Energy Corporation (NECSA), Pelindaba, North West \\ Province, South Africa \\ ${ }^{3}$ Fluoro-Materials Group, Department of Chemical Engineering, Faculty of Engineering, Built Environment \\ and Information Technology, University of Pretoria, Pretoria, South Africa \\ *Corresponding Author: Tel.: +2771 898 6674, E-mail address: jean@vanlaar.co.za
}

\begin{abstract}
A microwave plasma process operating at atmospheric pressure was developed for the synthesis of $\mathrm{SiC}$ nanoparticles. The process utilizes methyltrichlorosilane (MTS) as precursor, acting as both carbon and silicon source, along with an additional hydrogen feed to ensure a fully reducing reaction environment. In addition, argon served as carrier gas.. The parameters studied were the $\mathrm{H}_{2}$ :MTS molar ratio and the total enthalpy, in the range 0 to 10 and 70 to $220 \mathrm{MJ} / \mathrm{kg}$ respectively. The particles size distribution ranged from 15 to $140 \mathrm{~nm}$ as determined by SEM and TEM micrographs. It was found that an increase in enthalpy and a higher $\mathrm{H}_{2}$ :MTS ratio resulted in smaller SiC particle sizes. The adhesion of particles was a common ocuurence during the process, resulting in larger agglomerate sizes.
\end{abstract}

Keywords: silicon carbide, microwave plasma, nanoparticles, methyltrichlorosilane 


\section{Introduction}

The favourable physical and mechanical properties of silicon carbide ( $\mathrm{SiC}$ ) allow for various applications across many areas, e.g. in high power and high frequency electronics as well as high temperature technologies $[1,2]$. At present the material is receiving increased attention as a nuclear ceramic due to its excellent mechanical properties, low neutron absorption crosssection (25\% that of zirconium based alloys) and dimensional stability under irradiation [3]. While conventional carbide ceramics exhibit certain drawbacks, such as low ductility and high brittleness, nano-sized carbide powders can easily overcome these shortcomings.

SiC nanoparticles have been shown to exhibit properties that differ substantially from that of the bulk material, encouraging the creation of new areas of application. Many different maufacturing methods for the creation of $\mathrm{SiC}$ nanoparticles have been reported in the literature. These include carbothermic reduction [4], pulsed laser deposition [5], sol-gel processes [6], microwave heating [7,8] as well as different plasma techniques such as inductive radio-frequency (RF) [9]-[11], direct current (DC) thermal [12], low pressure microwave plasmas [13] and microwave plasma assisted chemical vapour deposition $[14,15]$. Vennekamp et al. [16] described the formation of a $\mathrm{SiC}$ nanopowder using an atmospheric microwave plasma with tetramethylsilane (TMS) as precursor. They also produced growthrate equations using the concept of Ostwald ripening, showing the dependency of particle growth rate on temperature and pressure. Microwave plasmas have also been used for the synthesis of other nanoscale substances such as $\mathrm{Si}$ [17], $\mathrm{MoS}_{2}$ and $\mathrm{WS}_{2}$ [18], $\mathrm{WO}_{3}$ [19] and $\mathrm{Zn}$ and $\mathrm{ZnO}[20]$.

It is well known that, given the right conditions, methyltrichlorosilane $\left(\mathrm{CH}_{3} \mathrm{SiCl}_{3}\right.$ or MTS) decomposes to form $\mathrm{SiC}$ and hydrogen chloride $(\mathrm{HCl})$ shown in Equation 1.

$$
\mathrm{CH}_{3} \mathrm{SiCl}_{3} \rightarrow \mathrm{SiC}+3 \mathrm{HCl}
$$

The reaction kinetics and mechanisms of this reaction have been thoroughly reported in the literature through chemical vapour deposition [21]-[24], chemical vapour infiltration [25], radio frequency induction plasma [26] and pyrolysis [27] investigations. In this paper the synthesis of SiC nanoparticles from MTS is reported using a microwave-induced plasma, operating at atmospheric pressure in an argon/hydrogen environment. Operation at atmospheric pressure allows for the possible development of low cost, less energy intensive 
synthesis methods and smaller equipment footprints. MTS was used as feed material due to the benefit of having a stoichiometric silicon-to-carbon elemental ratio, and the relative ease of the procedure through which MTS can be fed into the system due to its liquid state and high vapour pressure at standard conditions and high volatility.. Hydrogen was fed into the reactor along with the MTS as a reductant to drive the conversion reaction. The process parameters studied were the $\mathrm{H}_{2}$ :MTS molar ratio and the total enthalpy. Argon served as the carrier gas for MTS.

\section{Experimental}

\subsection{Apparatus}

A commercial microwave source from Electronic $\mathrm{GmbH} \&$ Co., Germany, model PGEN2450/1.5-1.5KW2AIW, was used. The equipment consists of a $1500 \mathrm{~W}$ power supply with a MOS-FET amplifier, a microwave generator operating at $2.45 \mathrm{GHz}$, a water-cooled magnetron head, a stub tuner, a rectangular waveguide and a sliding short. The quartz tube, in which the plasma is generated and maintained, was positioned through the middle- and perpendicular to the wave guide before the stub tuner. The quartz tube has an internal diameter of $2 \mathrm{~cm}$ and a length of $30 \mathrm{~cm}$. An in- and outlet at the top and bottom of the quartz tube allows for the flow of gas through the plasma. The tube was cooled by blowing air into an inlet into the waveguide perpendicular to the quartz tube and letting the air pass over the tube, exiting through the top and bottom openings in the waveguide. Argon and hydrogen flow rates were controlled using Aalborg rotameters. The physical layout of the reactor assembly is illustrated in Figure 1 and a schematic representation of the flow path is shown in Figure 2. 


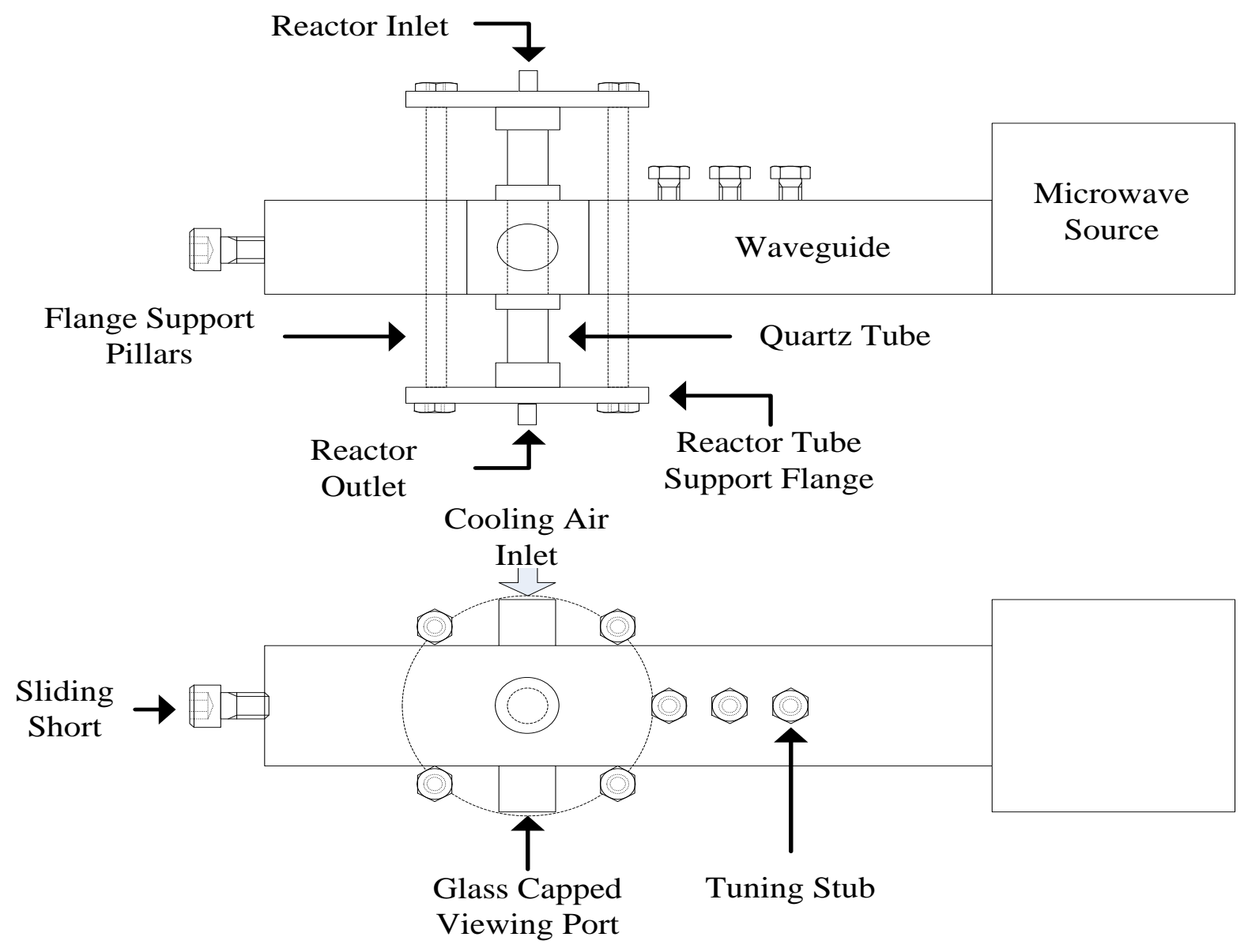

Figure 1: Physical layout of the reactor assembly.

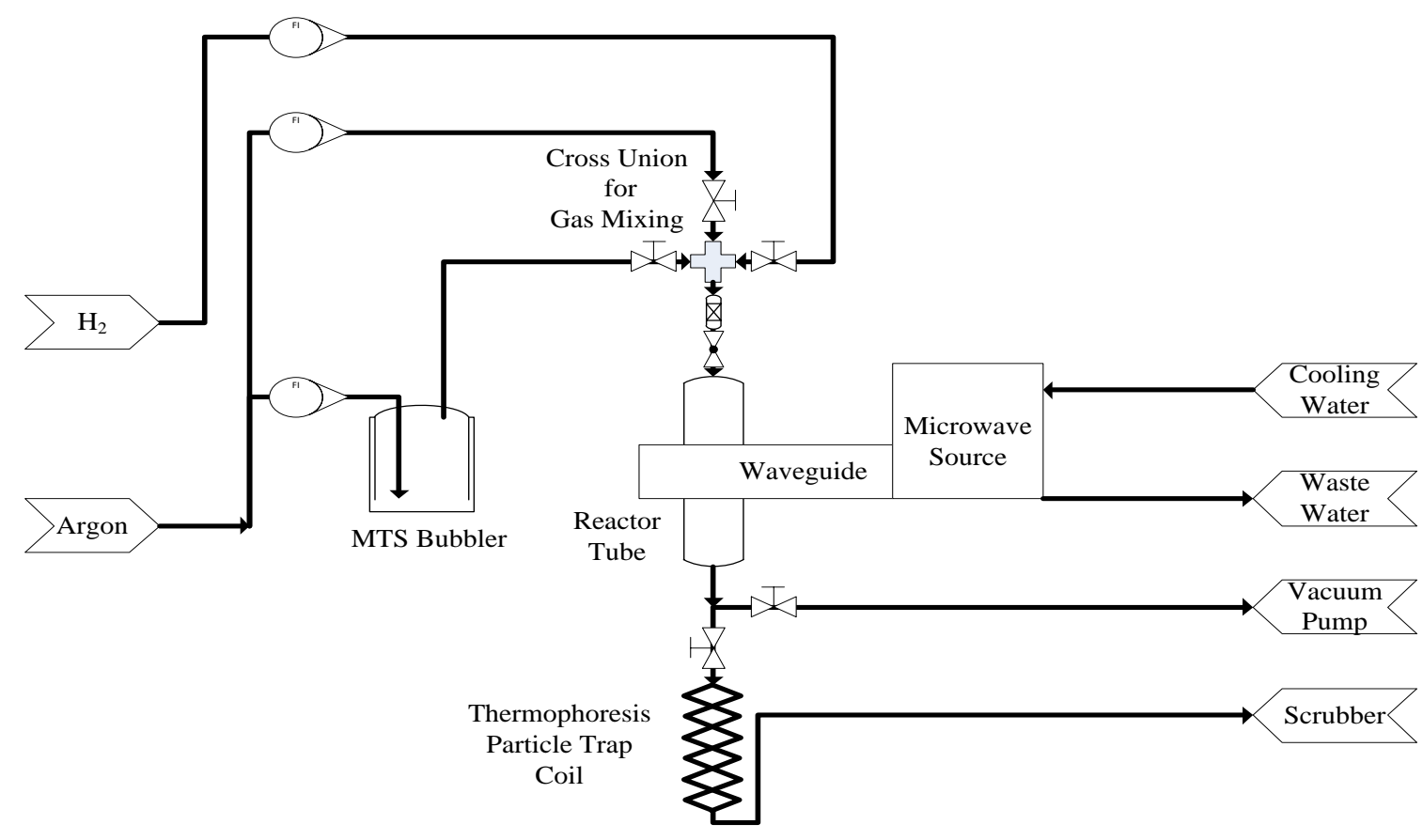

Figure 2: Schematic representation of the flow path of the experimental assembly. 
MTS vapour was fed into the reactor by vaporising MTS into a bypass argon stream and passing the MTS laden argon into a cross joint where it was mixed with the main argon stream and the hydrogen feed. The total gaseous feed mixture was passed through a 0.2 micron sintered metal filter to ensure that no solid materials enter the plasma reactor and that the total gas mixture is homogenously mixed. The mass flow of MTS was controlled by varying the bubbling rate of the argon carrier.. The MTS mass transfer as a function of argon flow rate in standard cubic centimeters per minute $(\mathrm{sccm})$ is shown in Figure 3 . The calibration curve was determined by bubbling argon through the liquid MTS at different flow rates for 10 minutes each, and measuring the mass difference after each run.

The MTS vaporisation assembly consisted of a $250 \mathrm{~mL}$ borosilicate glass jar equipped with a lid containing an inlet and outlet port. The argon inlet line was placed below the level of the MTS. The inlet line was left open and the argon allowed to bubble freely.

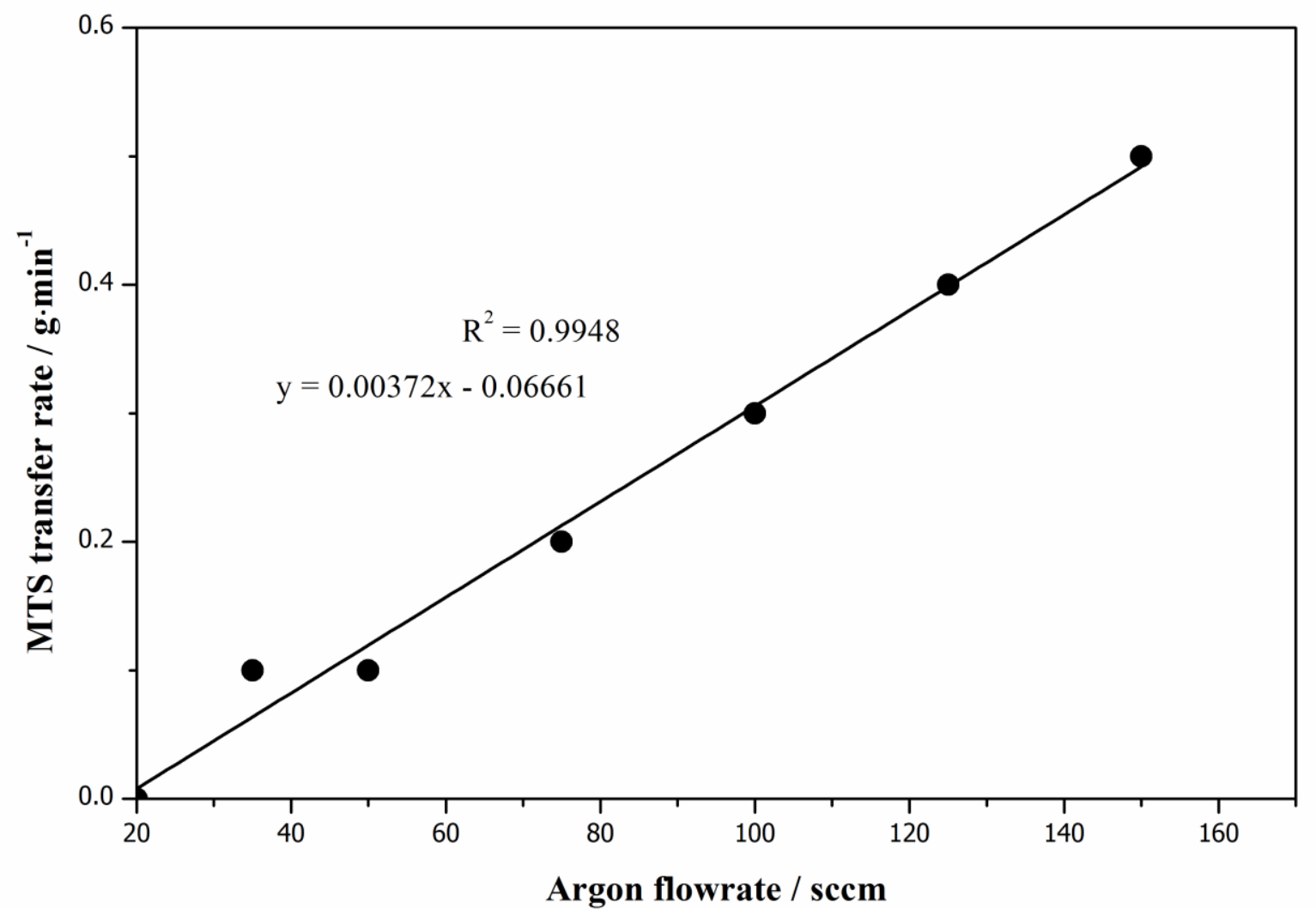

Figure 3: MTS mass transfer calibration curve.

Some physical properties of MTS are given in Table 1 [28]. 
Table 1: Physical properties of MTS [28].

\begin{tabular}{lll}
\hline Property & Value & Units \\
\hline Molecular weight & 149.48 & $\mathrm{~g} / \mathrm{m}$ \\
Boiling point & 65 & ${ }^{\circ} \mathrm{C}$ \\
Melting point & -90 & ${ }^{\circ} \mathrm{C}$ \\
Specific gravity & $1.270 @ 25^{\circ} \mathrm{C}$ & \\
Vapor density & $5.17(\mathrm{Air}=1)$ & \\
Vapour pressure & $167 @ 25^{\circ} \mathrm{C}$ & $\mathrm{mm} \mathrm{Hg}$ \\
\hline
\end{tabular}

The exit gas from the reactor was passed through a coiled 1/4" copper thermophoresis tube, cooled by immersing the tube in an ice bath, to collect any product particles, then passing the exit gas into a $\mathrm{NaOH}$ scrubber to remove $\mathrm{HCl}$ and any unreacted MTS before releasing the stream into an extraction system.

A T-connection and valve assembly in the reactor outlet line enabled the selection between evacuation of the reactor tube or operation without vacuum whilst still providing a straight, unrestricted flow path form the reactor outlet to the phoresis tube for product collection.

Particle size distribution was determined through the use of a ZEN 3600 Malvern Zetasizer Nano System. Scanning electron microscopy (SEM) was performed on the particles using a high resolution (6 ̊) JEOL 6000 system and transmission electron microscopy (TEM) was performed using the Phillips 301 instrument. Emission spectrographs were recorded with an Ocean Optics, HR 4000 High-Resolution Spectrometer. The optical input to the spectrometer for the emission lines was obtained by positioning the optical input cable onto the quartz tube.

Powder x-ray diffraction was conducted with a PANalytical X pert Pro diffractometer using Co $\mathrm{K}_{\alpha}$ radiation. The peak assignments were made using the databases supplied from the instrument manufacturer.

\subsection{Experimental method}

The argon plasma was initiated under vacuum ( $2 \times 10^{-3}$ mbar), using an Alcatel 2010I duelstage rotary vane pump. The pressure was then gradually increased to atmospheric pressure where filamentation of the plasma structure occurred [29]. At this pressure the hydrogen and MTS were fed into the system. Depending on the hydrogen-to-MTS ratio, stable plasmas 
could be maintained at applied powers between 200 and 1500 W. High hydrogen concentrations tended to starve and extinguish the plasma. High MTS content resulted in a "dusty" plasma [30]. Black powder deposited on the inner wall of the quartz tube and were removed after each experimental run using distilled water. The water was evaporated in a drying oven operating at $50{ }^{\circ} \mathrm{C}$ and the powders were collected.

The experimental parameters are shown in Table 2. All values were selected to cover a wide range of experimental parameters, within the capability of the system.

Table 2: Experimental parameters

\begin{tabular}{ccccc}
\hline $\begin{array}{c}\text { Exp. } \\
\text { number }\end{array}$ & $\begin{array}{c}\text { Ar flow } \\
(\mathrm{sccm})\end{array}$ & $\begin{array}{c}\text { MTS flow } \\
(\mathrm{g} / \mathrm{h})\end{array}$ & $\begin{array}{c}\mathrm{H}_{2} \text { :MTS } \\
(\mathrm{mol}: \mathrm{mol})\end{array}$ & $\begin{array}{c}\text { Power } \\
(\mathrm{W})\end{array}$ \\
\hline 1 & 150 & 2.64 & 4.0 & 400 \\
2 & 150 & 2.64 & 7.4 & 570 \\
3 & 150 & 2.64 & 9.3 & 560 \\
4 & 150 & 2.64 & 7.4 & 1300 \\
5 & 150 & 2.64 & 4.0 & 1500 \\
6 & 150 & 2.64 & 1.3 & 1300 \\
7 & 150 & 2.64 & 0 & 870 \\
8 & 150 & 2.64 & 1.3 & 570 \\
9 & 150 & 2.64 & 4.0 & 950 \\
10 & 150 & 2.64 & 4.0 & 950 \\
11 & 150 & 2.64 & 4.0 & 950 \\
12 & 150 & 2.64 & 4.0 & 1500 \\
\hline
\end{tabular}




\section{Results and discussion}

The experimental results are shown in Table 3. Note that the enthalpy value given is the system enthalpy, which applies to all the components (argon, hydrogen and MTS) combined. The enthalpy values, $H_{T O T}$, were determined by Equation 2

$$
H_{T O T}=\frac{P_{f}}{M_{T O T}}
$$

where $P_{f}$ is the forwarded power and $M_{T O T}$ is the total mass flow rate. In general, particle agglomerates were obtained. The aggregate particle sizes $\left(\mathrm{d}_{50}\right)$ and the individual particle sizes obtained are both listed in Table 3. Experiment no. 3 yielded no results due to the continuous extinguishing of the plasma, the cause of which is expected to be the high $\mathrm{H}_{2}$ :MTS ratio of 9.3. As mentioned before, at these high levels the hydrogen tends to starve and extinguish the plasma. The running time is the total time measured from the point where MTS was introduced into the stable argon/hydrogen plasma (already operating at atmospheric pressure). The end of the time measurement was taken to be either after three minutes of stable operation or the longest time that a stable plasma could be maintained before extinguishing itself.

Based on the results, the best fitted-model included quadratic and 2-factor interaction terms. The analysis of variance (ANOVA) for the agglomerate sizes is presented in Table 4. 
Table 3: Summary of experimental results.

\begin{tabular}{ccccccc}
\hline $\begin{array}{c}\text { Exp. } \\
\text { number }\end{array}$ & $\begin{array}{c}\text { Enthalpy } \\
(\mathrm{MJ} / \mathrm{kg})\end{array}$ & $\begin{array}{c}\text { Average particle } \\
\text { size of }\end{array}$ & $\begin{array}{c}\text { Average particle } \\
\text { size of individual }\end{array}$ & $\begin{array}{c}\text { Run Time } \\
(\mathrm{s})\end{array}$ & $\begin{array}{c}\text { SiC } \\
\text { production }\end{array}$ & $\begin{array}{c}\text { SiC } \\
\text { yield }\end{array}$ \\
& & $\begin{array}{c}\text { agglomerates, } \mathrm{d}_{50} \\
\text { particles, } \mathrm{d}_{50}\end{array}$ & $\begin{array}{c}\text { rate } \\
(\mathrm{nm})\end{array}$ & $\begin{array}{c}\mathrm{n}) \\
(\mathrm{g} / \mathrm{h})\end{array}$ & \\
\hline 1 & 71.7 & 1296 & 89 & 18 & 1.40 & 14 \\
2 & 101.6 & 1743 & 82 & 20 & 0.18 & 2 \\
3 & 108.7 & - & - & - & - & - \\
4 & 196.0 & 461 & 68 & 70 & 1.19 & 12 \\
5 & 197.2 & 483 & 111 & 180 & 2.35 & 24 \\
6 & 162.1 & 590 & 53 & 180 & 1.00 & 10 \\
7 & 102.9 & 1233 & 132 & 180 & 0.56 & 6 \\
8 & 102.7 & 800 & 132 & 180 & 2.25 & 23 \\
9 & 152.4 & 744 & 110 & 223 & 0.74 & 9 \\
10 & 152.4 & 634 & 131 & 148 & 0.87 & 9 \\
11 & 152.4 & 675 & 91 & 180 & 1.20 & 12 \\
12 & 215.1 & 475 & 121 & 180 & 0.74 & 7 \\
\hline
\end{tabular}

Table 4: ANOVA for Response Surface quadratic model of Zetasizer results.

\begin{tabular}{lllllll}
\hline & Sum of & & Mean & F & p-value & \\
Source & Squares & Df & Square & Value & Prob > F & \\
\hline Model & 1600171.00 & 5 & 320034.30 & 12.92 & 0.0070 & Significant \\
A-Enthalpy & 765238.10 & 1 & 765238.10 & 30.88 & 0.0026 & \\
B-H ${ }_{2}$ MTS & 51635.30 & 1 & 51635.30 & 2.08 & 0.2085 & \\
AB & 177041.70 & 1 & 177041.70 & 7.14 & 0.0442 & \\
A $^{2}$ & 42770.98 & 1 & 42770.98 & 1.73 & 0.2460 & \\
B $^{2}$ & 194981.50 & 1 & 194981.50 & 7.87 & 0.0378 & \\
Residual & 123893.20 & 5 & 24778.65 & & & Not significant \\
Lack of Fit & 117712.60 & 3 & 39237.52 & 12.70 & 0.0739 & \\
Pure Error & 6180.67 & 2 & 3090.33 & & & \\
Cor Total & 1724065.00 & 10 & & & & \\
\hline
\end{tabular}


The ANOVA results indicate a model F-value of 12.92 and p-value $<0.05$. Enthalpy has the greatest effect on the agglomerate sizes whereas $\mathrm{H}_{2}$ :MTS ratio was found to be least significant. In addition, the lack of fit of model was not significant. Model regression results are presented in Table 5.

Table 5: Model regression results for agglomerate sizes.

\begin{tabular}{cccc}
\hline R-Squared & Adj R-Squared & Pred R-Squared & Adeq Precision \\
\hline 0.93 & 0.86 & -0.05 & 11.07 \\
\hline
\end{tabular}

The reasonable correlation coefficient (0.93) of the model indicates good agreement between the experimental and predicted data.

The analysis of variance (ANOVA) for the individual particle sizes is presented in Table 6.

Table 6: ANOVA for Response Surface quadratic model of SEM results.

\begin{tabular}{|c|c|c|c|c|c|c|}
\hline Source & $\begin{array}{l}\text { Sum of } \\
\text { Squares }\end{array}$ & $\mathrm{df}$ & $\begin{array}{l}\text { Mean } \\
\text { Square }\end{array}$ & $\begin{array}{l}\mathrm{F} \\
\text { Value }\end{array}$ & $\begin{array}{l}\text { p-value } \\
\text { Prob }>F\end{array}$ & \\
\hline Model & 2262.17 & 5 & 452.43 & 0.43 & 0.81 & Not significant \\
\hline A-Enthalpy & 112.82 & 1 & 112.82 & 0.10 & 0.76 & \\
\hline B-H ${ }_{2}: M T S$ & 585.03 & 1 & 585.03 & 0.56 & 0.49 & \\
\hline $\mathrm{AB}$ & 661.22 & 1 & 661.22 & 0.63 & 0.46 & \\
\hline $\mathrm{A}^{2}$ & 2.96 & 1 & 2.96 & 0.00 & 0.96 & \\
\hline $\mathrm{B}^{2}$ & 762.94 & 1 & 762.94 & 0.73 & 0.43 & \\
\hline Residual & 5211.65 & 5 & 1042.33 & & & \\
\hline Lack of Fit & 4378.24 & 3 & 1459.41 & 3.50 & 0.23 & Not significant \\
\hline Pure Error & 833.41 & 2 & 416.71 & & & \\
\hline Cor Total & 7473.82 & 10 & & & & \\
\hline
\end{tabular}

The Model F-value of 0.43 implies the model is not significant relative to the noise. There is an $80.95 \%$ chance that an F-value this large could occur due to noise. Values of "Prob > F" less than 0.0500 indicates the model terms are significant. In this case there are no significant model terms. Model regression results are presented in Table 7. 
Table 7: Model regression results for individual particle sizes.

\begin{tabular}{cccc}
\hline R-Squared & Adj R-Squared & Pred R-Squared & Adeq Precision \\
\hline 0.30 & -0.39 & -15.93 & 2.31 \\
\hline
\end{tabular}

From these results it becomes clear that this model should not be used to navigate the design space, and caution is advised when doing so.

Application of response surface analysis (RSA) on the Zetasizer and SEM results yields the surface contour plots shown in Figure 4 and Figure 5 respectively. The individual particle size distribution indicates that the particle size decreases when the power and the $\mathrm{H}_{2}$ :MTS ratio increases. The agglomerate particle size distribution shows that, as expected, lower enthalpies produce larger agglomerates, but that the agglomeration process is much more sensitive to $\mathrm{H}_{2}$ :MTS ratios with higher ratios negatively influencing the agglomerate size.

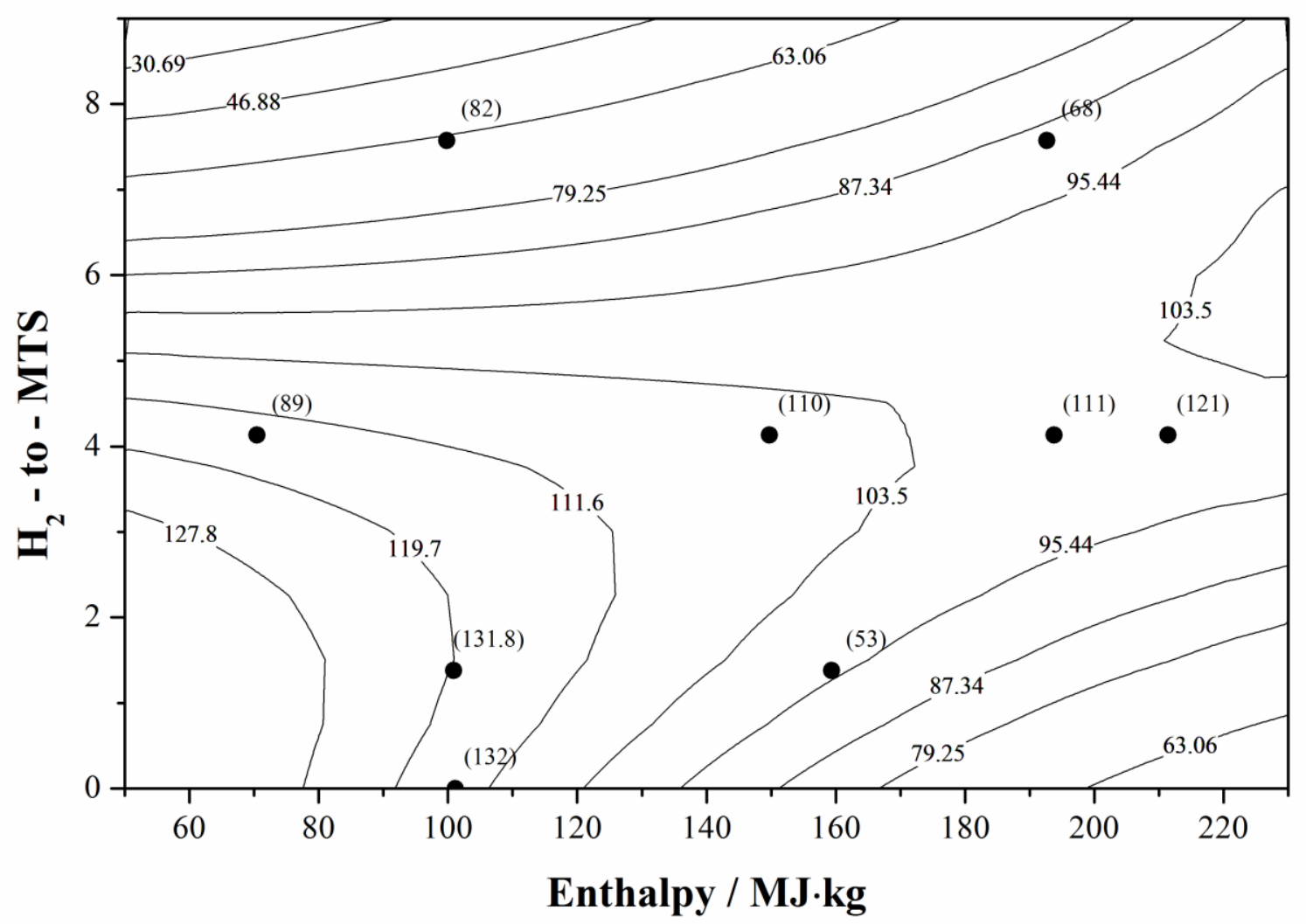

Figure 4: Effect of total enthalpy and $\mathrm{H}_{2}$ :MTS molar ratio on individual particle size. 


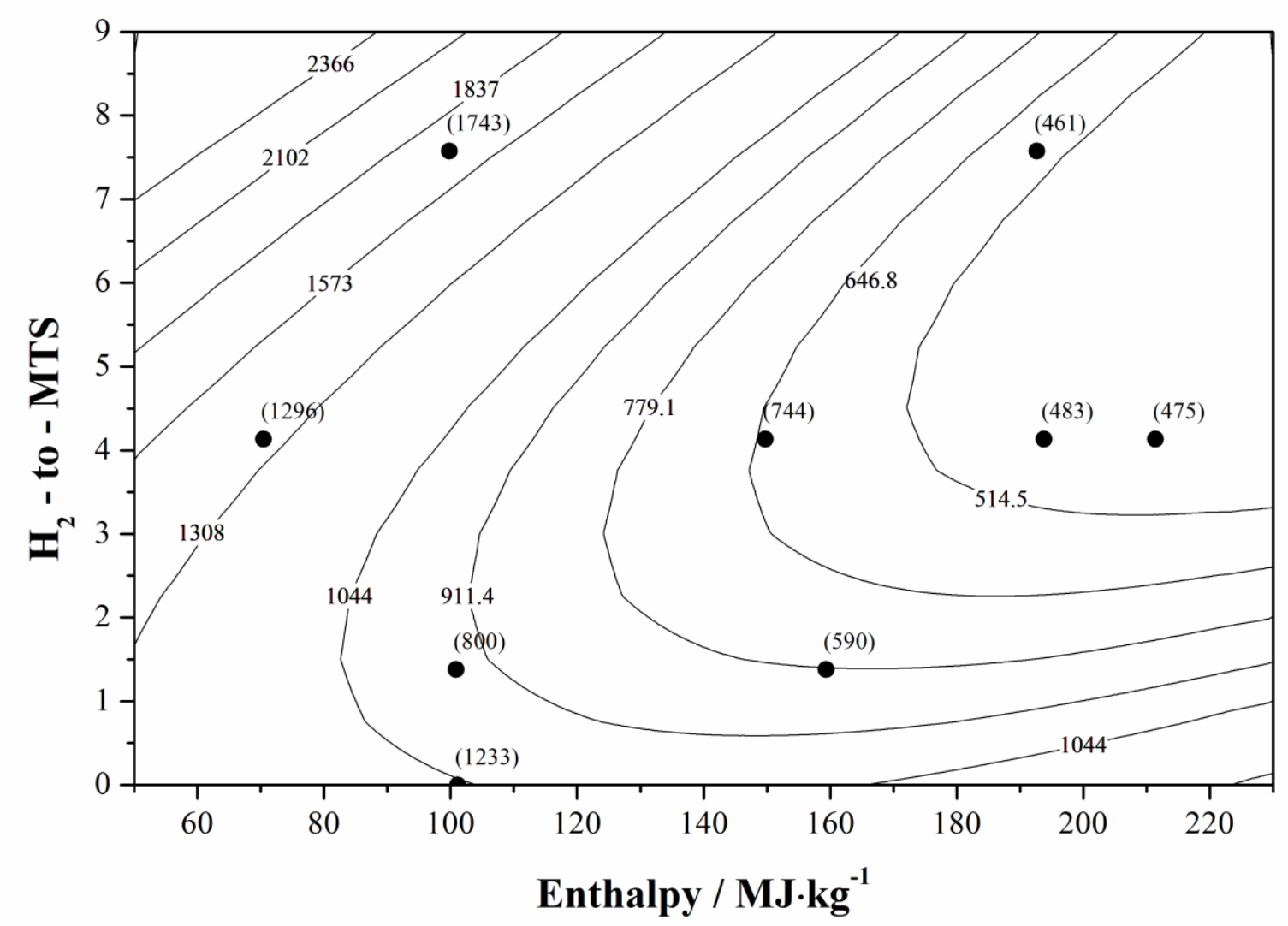

Figure 5: Effect of total enthalpy and $\mathrm{H}_{2}$ :MTS molar ratio on agglomerate size.

Figure 6 to Figure 9 present SEM and TEM micrographs, which show individual particle sizes of between 15 and $140 \mathrm{~nm}$. These sizes are larger than those reported by Vennekamp et al. [16] who used tetramethylsilane (TMS) as precursor. Particles displayed a large degree of agglomeration, as is reflected in the large difference in SEM particle sizes when compared to the Zetasizer results. 


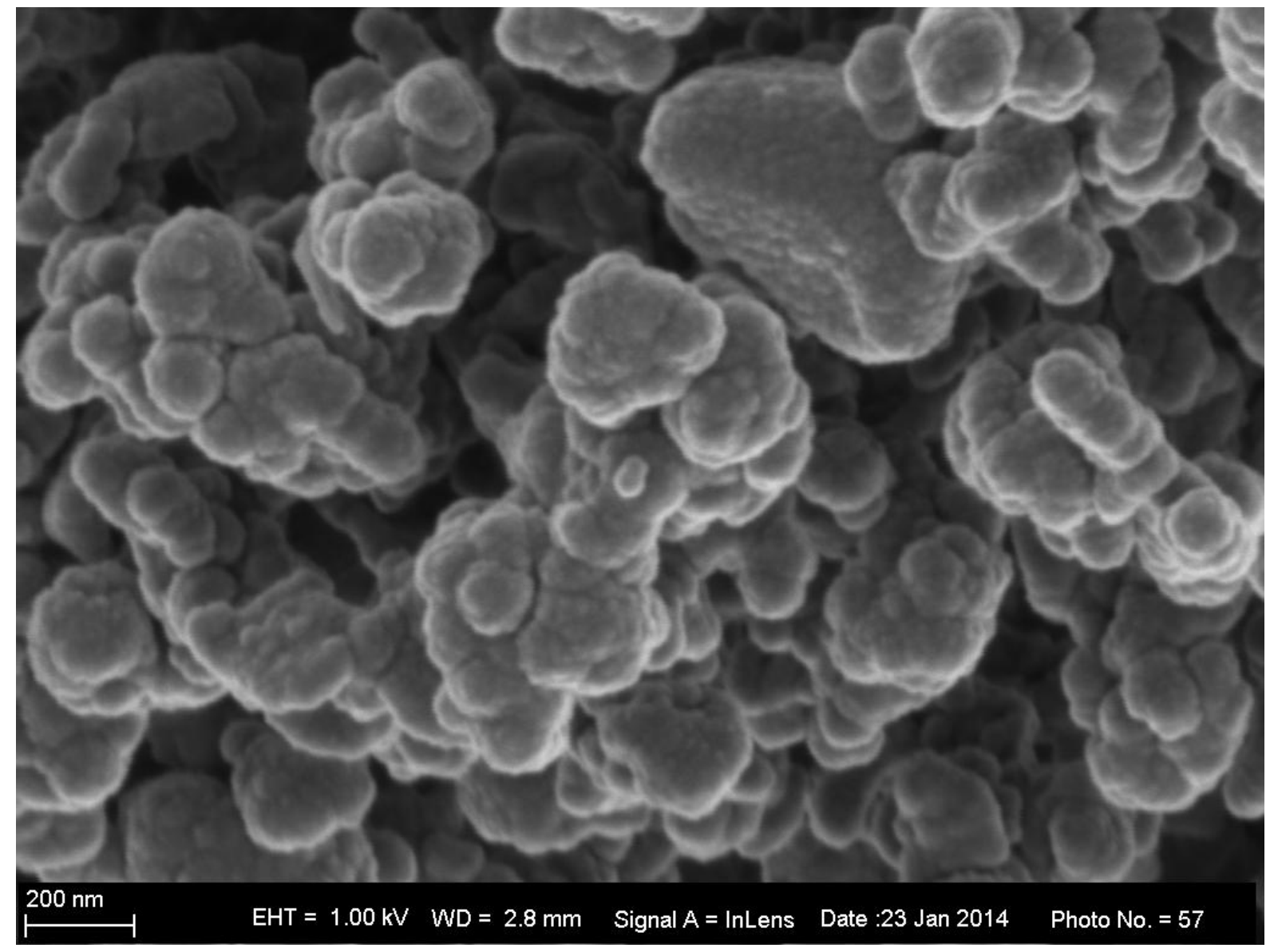

Figure 6: SEM images of sample 11. 


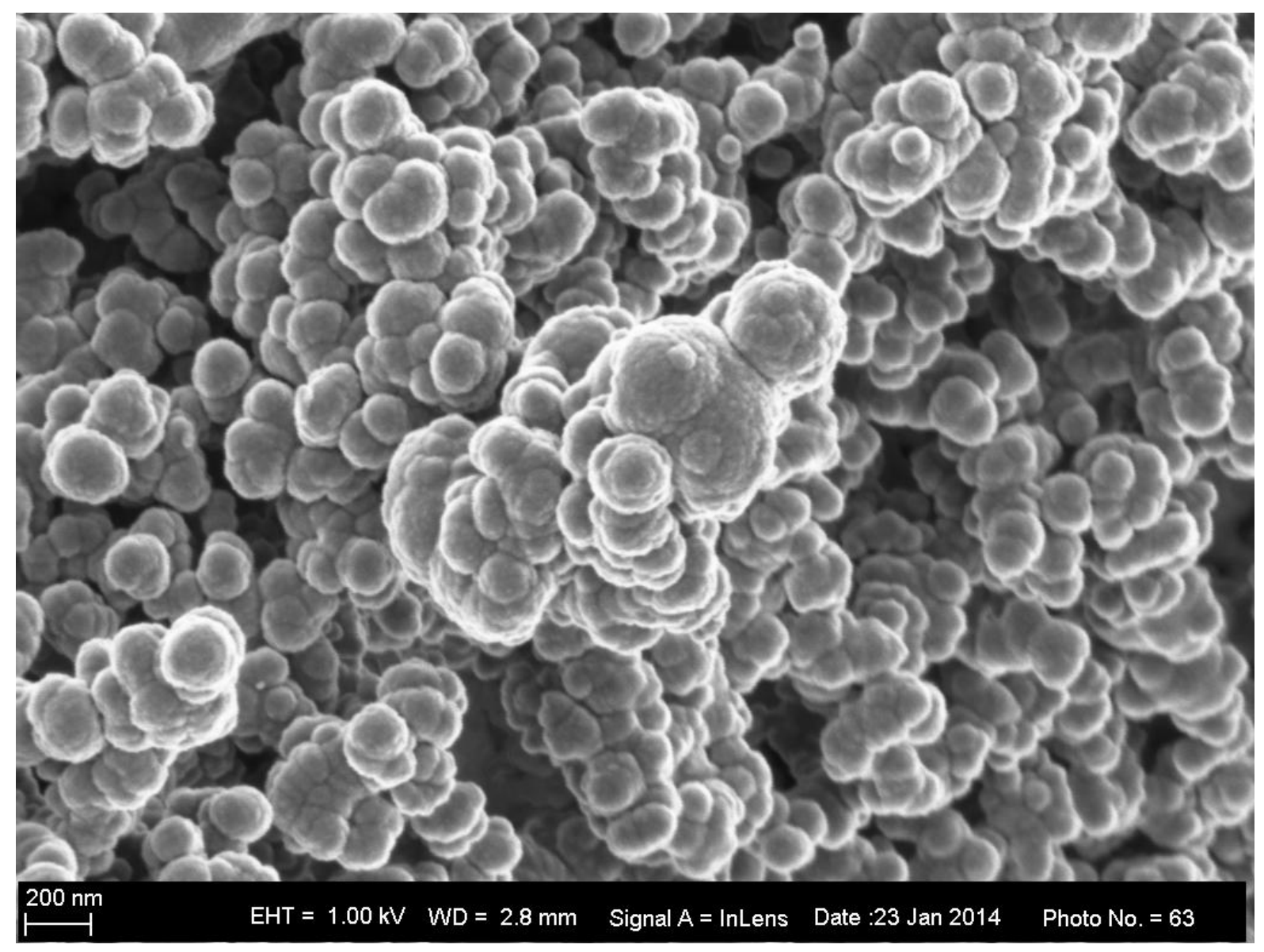

Figure 7: SEM image of sample 12. 


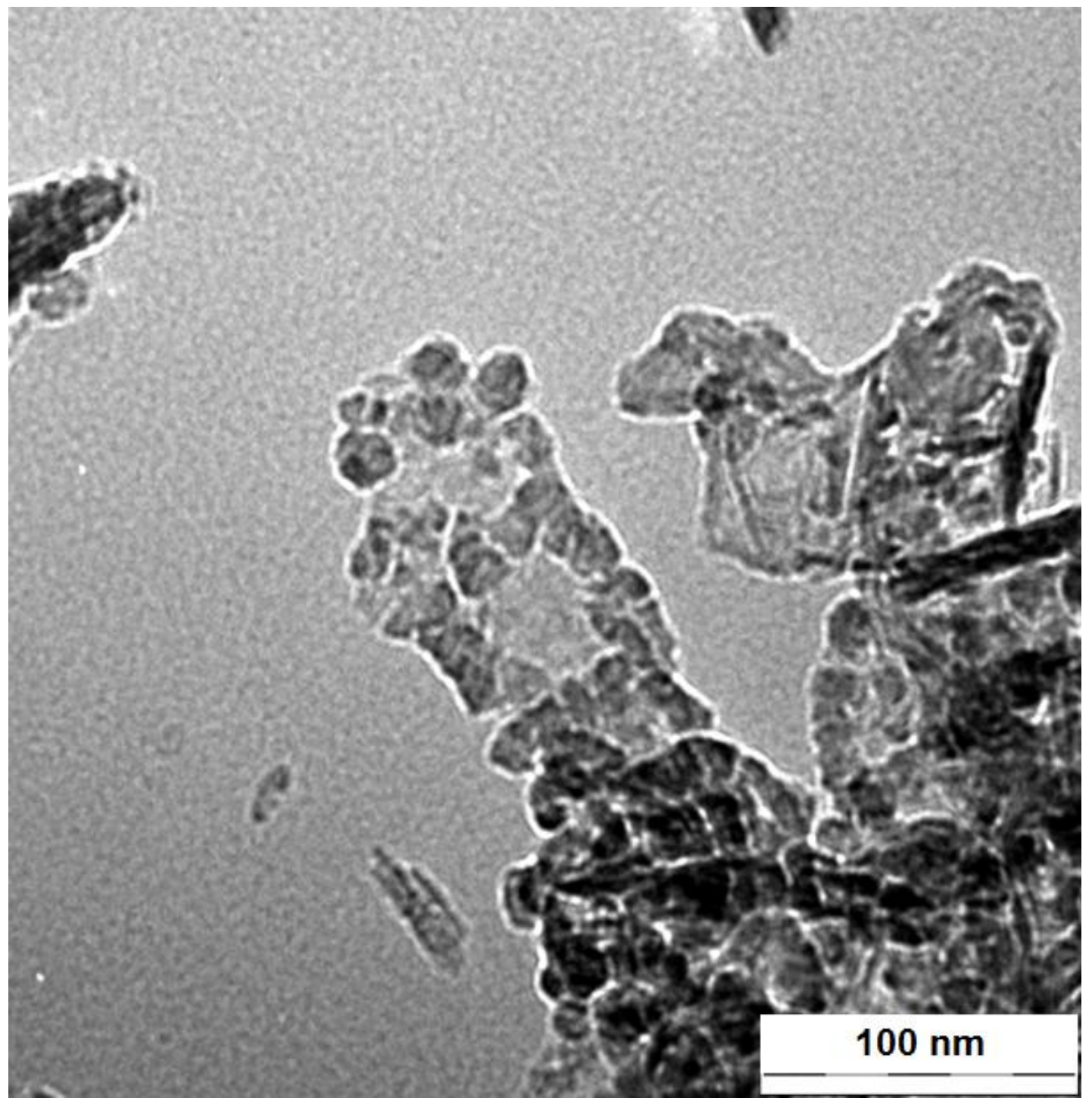

Figure 8: TEM image of sample 6 . 


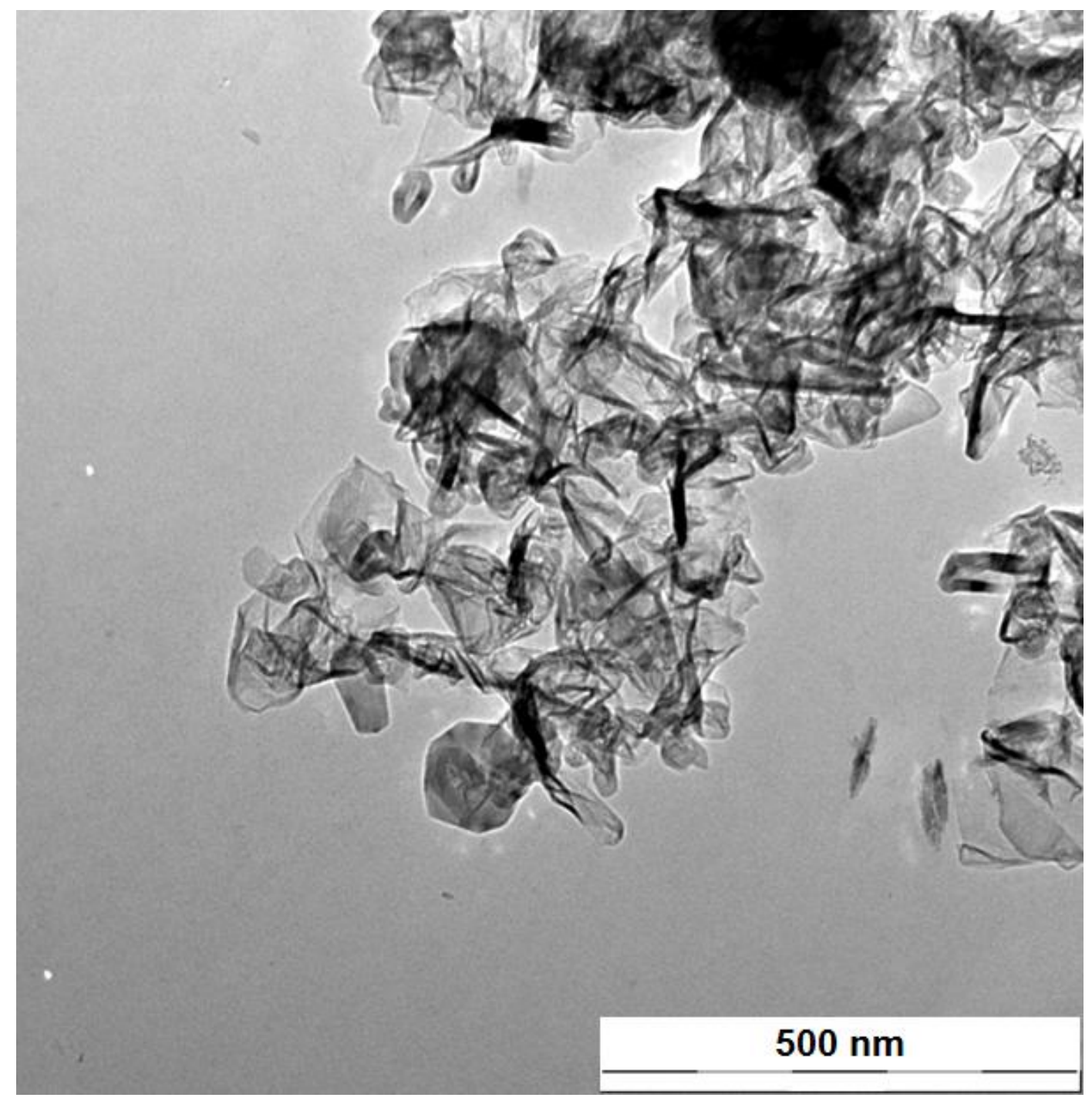

Figure 9: TEM image of sample 6.

Similar structures, with smaller particle sizes, were reported by Lin et al. [13] when operating at low pressures and using TMS. X-ray diffraction results show diffraction peaks at positions typical of $\beta-\mathrm{SiC}$ (cubic) as seen in Figure 10. Interestingly, the diffraction peaks for cubic silicon is also seen. 


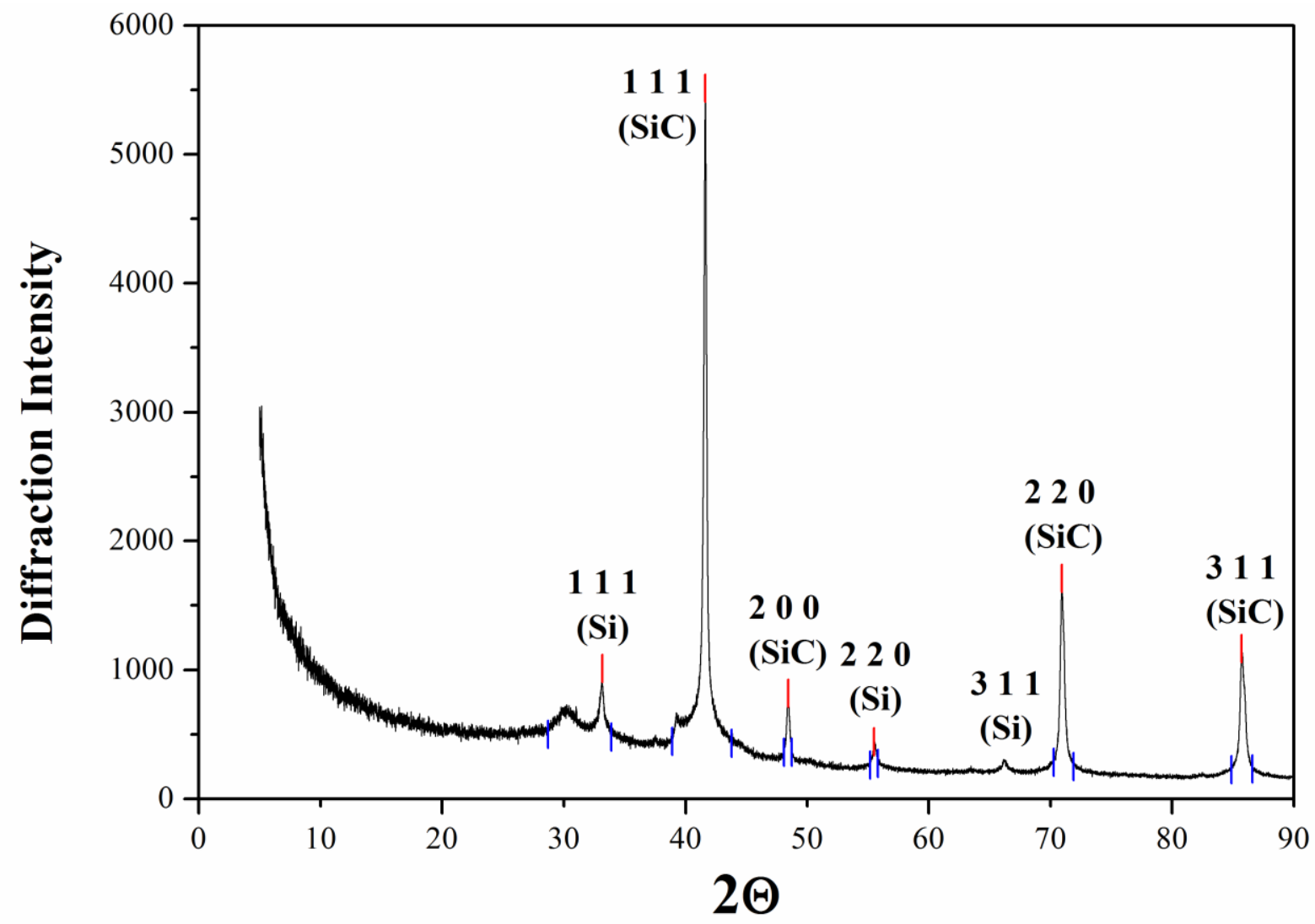

Figure 10: XRD spectrum of a product sample synthesised at an $\mathrm{H}_{2}$ :MTS ratio of 4 . SiC refers to the $\beta$ phase.

An optical emission spectrometer was used in order to determine the elements present in the plasma environment. This is a standard diagnostic tool often used to monitor discharge emissions [31]. An emission spectrum for wavelengths $200-1100 \mathrm{~nm}$ is shown in Figure 11. A few are obviously expected to be that of argon. The growth of nanoparticles in the plasma can drastically change the plasma properties. Layden et al. [32] performed optical emission spectroscopy on an RF sputtering discharge in argon during dust particle growth to analyse this change. They found that the intensities of all of the argon emission lines increase, indicating an increase in the number of high energy electrons as a result of particle growth. The majority of peaks in this case were in good agreement with experimental values of elementary silicon, carbon and argon [33]-[36], indicative of MTS decomposition in the plasma.

The presence of elementary silicon in the gas phase as well as silicon in the product material suggests that the addition of hydrogen to the plasma drives the conversion reactions too far into the reductive regime. 


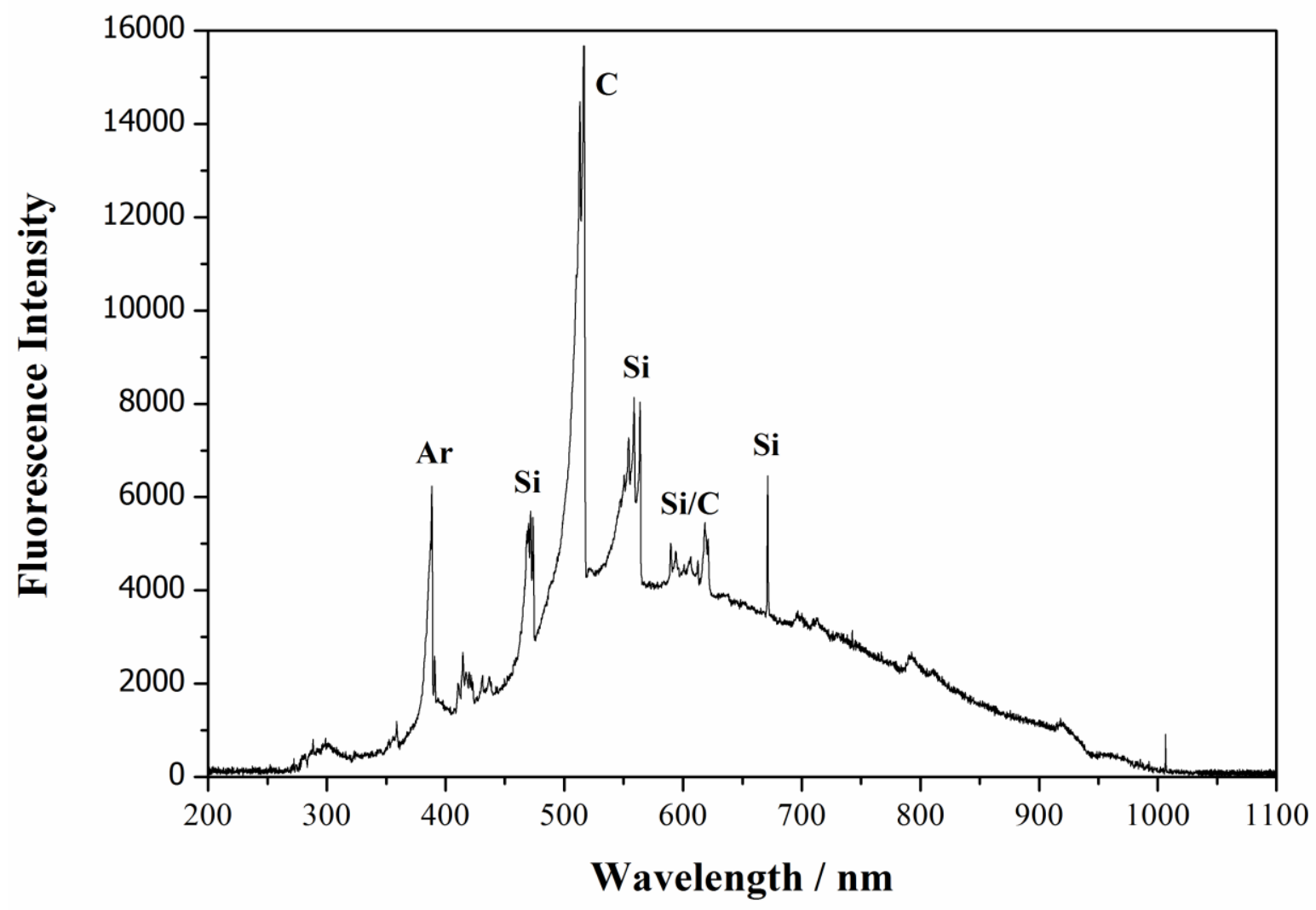

Figure 11: Emission spectrograph (Experiment 4).

The equilibrium thermodynamics and formation mechanisms of Equation 1 have been reported in the literature [37]. The optimum conditions for the formation of $\beta$-SiC are confirmed in Figure 12 using the thermodynamics software package TERRA [38]. At temperatures of around $1400 \mathrm{~K}$, optimum yield for $\beta$-SiC formation is obtained. Microwave plasmas can operate anywhere within the region of 1400-10 $000 \mathrm{~K}$ [39]. This experiment operated between 1500 and $1900 \mathrm{~K}$. Exact control of the gas temperature was not attempted or measured during this experiment due to the complicated nature of such an exercise. The enthalpy required to convert MTS into $\mathrm{SiC}$ is calculated using the assumption of thermodynamic equilibrium, shown in Figure 13. The experimental specific enthalpy values listed in Table 3 are significantly lower than the thermal values of Figure 13, suggesting that the non-equilibrium nature of the plasma plays a significant role in the MTS decomposition process. 


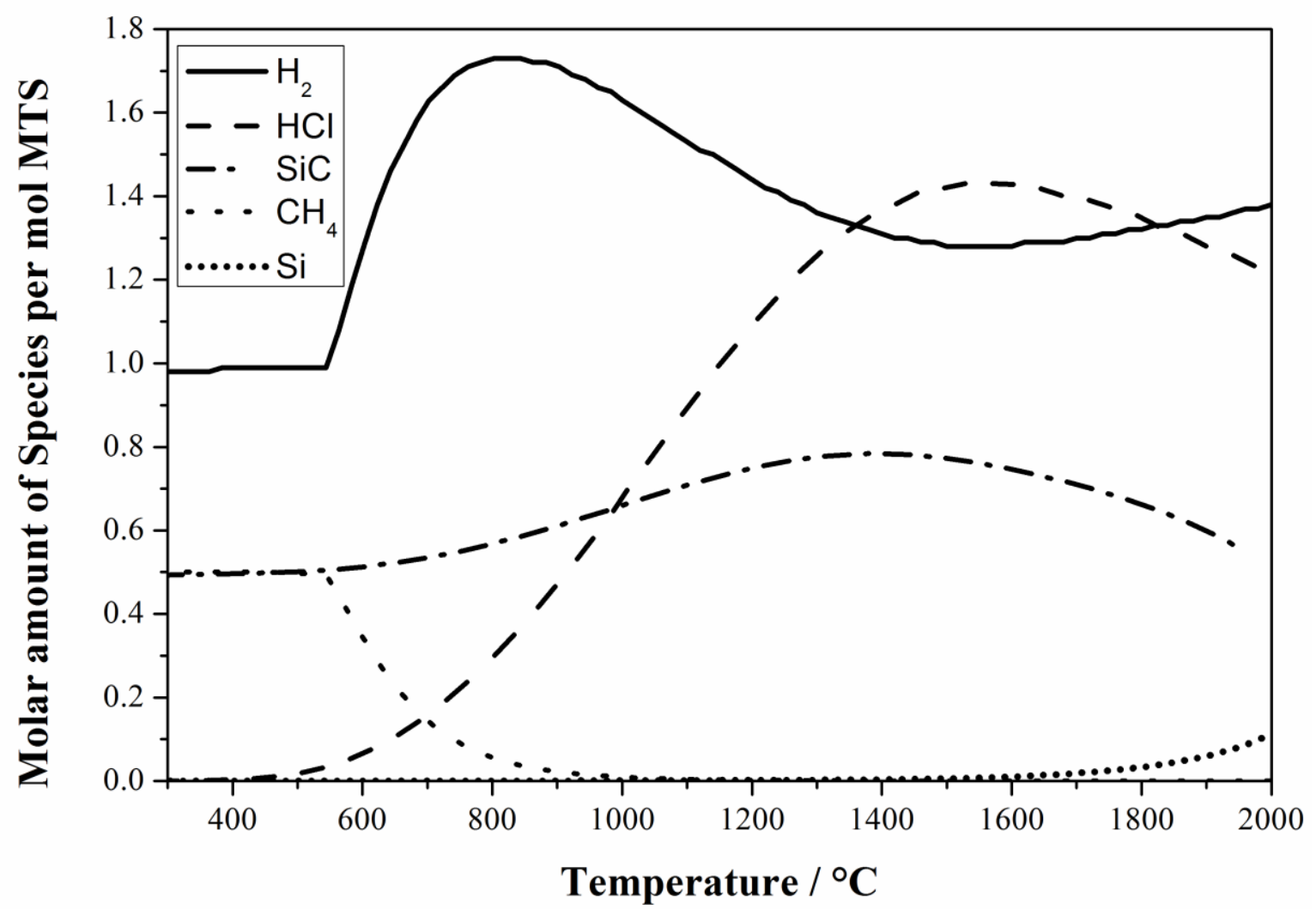

Figure 12: Equilibrium temperature dependent speciation curves. 


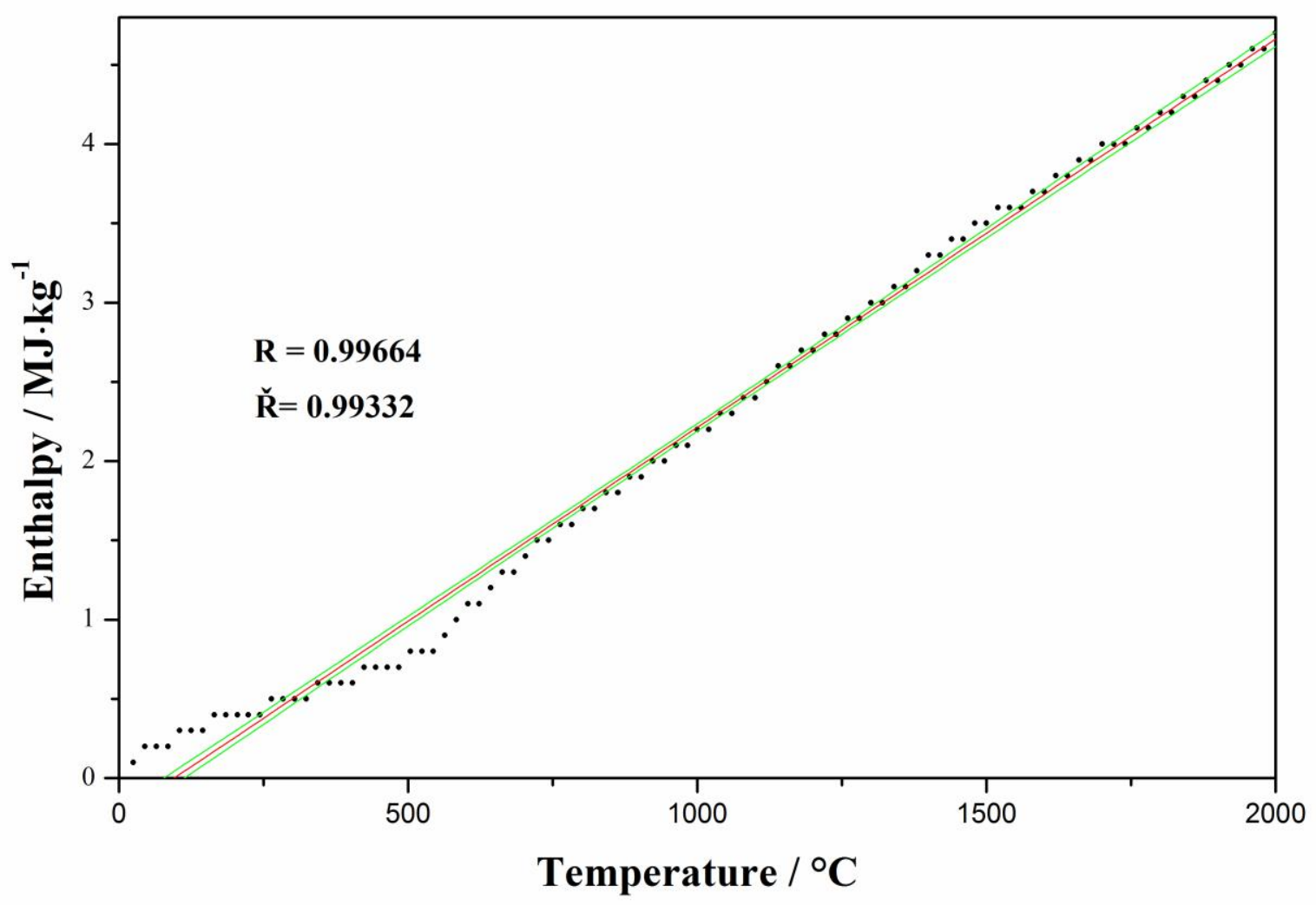

Figure 13: Specific enthalpy for MTS.

\section{Conclusions}

Methyltrichlosilane decomposes in a microwave plasma reactor to form SiC nanoparticles. Particle sizes range between 15 and $140 \mathrm{~nm}$, confirmed by SEM and TEM characterization. These particles form agglomerates resulting in large particle sizes, as measured by Zetasizer. $\mathrm{X}$-ray diffraction studies confirmed the presence of $\beta$-SiC and elemental $\mathrm{Si}$ in the product material. The process parameters studied were the $\mathrm{H}_{2}$ :MTS molar ratio and the total enthalpy. An inverse correlation was observed between enthalpy and the particle size. A similar correlation was observed for $\mathrm{H}_{2}$ :MTS ratio and particle size. The addition of hydrogen to the plasma complicates the production of pure $\mathrm{SiC}$ by the method reported here.

Acknowledgements: The authors acknowledge the South African National Research Foundation for financial support, and the South African Nuclear Energy Corporation for use of their equipment. 


\section{References}

[1] G. L. Harris, Properties of Silicon Carbide. Washington DC, USA: INSPEC, 1995.

[2] S. Saddow and A. Agarwal, Advances in silicon carbide processing and applications. Norwood, USA: ARTECH HOUSE, INC, 2004.

[3] Y. Katoh, L. L. Snead, I. Szlufarska, and W. J. Weber, "Radiation effects in SiC for nuclear structural applications," Curr. Opin. Solid State Mater. Sci., vol. 16, no. 3, pp. 143-152, 2012.

[4] S. Dhage, H.-C. Lee, M. S. Hassan, M. S. Akhtar, C.-Y. Kim, J. M. Sohn, K.-J. Kim, H.-S. Shin, and O.-B. Yang, "Formation of $\mathrm{SiC}$ nanowhiskers by carbothermic reduction of silica with activated carbon," Mater. Lett., vol. 63, no. 2, pp. 174-176, Jan. 2009.

[5] D. B. Chrisey and G. K. Hubler, Pulsed Laser Deposition of Thin Films. New York: Wiley \& Sons, 1994.

[6] J. Li, J. Tian, and L. Dong, "Synthesis of SiC precursors by a two-step sol-gel process and their conversion to SiC powders," J. Eur. Cermaic Soc., vol. 77, pp. 1853-1857, 2000 .

[7] L. N. Satapathy, P. D. Ramesh, D. Agrawal, and R. Roy, "Microwave synthesis of phase-pure, fine silicon carbide powder," Mater. Res. Bull., vol. 40, no. 2005, pp. 1871-1882, 2005.

[8] B. M. Moshtaghioun, R. Poyato, F. L. Cumbrera, S. de Bernardi-Martin, A. Monshi, M. H. Abbasi, F. Karimzadeh, and A. Dominguez-Rodriguez, "Rapid carbothermic synthesis of silicon carbide nano powders by using microwave heating," J. Eur. Ceram. Soc., vol. 32, no. 8, pp. 1787-1794, Jul. 2012.

[9] Z. Károly, I. Mohai, S. Klébert, a. Keszler, I. E. Sajó, and J. Szépvölgyi, "Synthesis of SiC powder by RF plasma technique," Powder Technol., vol. 214, no. 3, pp. 300-305, Dec. 2011.

[10] H. Sachdev and P. Scheid, "Formation of silicon carbide and silicon carbonitride by RF-plasma CVD,” Diam. Relat. Mater., vol. 10, no. 3-7, pp. 1160-1164, Mar. 2001.

[11] S.-M. Ko, S.-M. Koo, W.-S. Cho, K.-T. Hwnag, and J.-H. Kim, "Synthesis of SiC nano-powder from organic precursors using RF inductively coupled thermal plasma," Ceram. Int., vol. 38, no. 3, pp. 1959-1963, Apr. 2012.

[12] B. Kim and B. Lee, "Effect of Plasma and Control Parameters on SiC Etching in a C 2 F 6 Plasma," Plasma Chem. Plasma Process., vol. 23, no. 3, pp. 489-499, 2003.

[13] H. Lin, J. A. Gerbec, M. Sushchikh, and E. W. Mcfarland, "Synthesis of amorphous silicon carbide nanoparticles in a low temperature, low pressure plasma reactor," Nanotechnology, vol. 19, no. 325601, pp. 1-8, 2008. 
[14] C. Tang, L. Fu, a. J. S. Fernandes, M. J. Soares, G. Cabral, a. J. Neves, and J. Grácio, "Simultaneous formation of silicon carbide and diamond on Si substrates by microwave plasma assisted chemical vapor deposition," New Carbon Mater., vol. 23, no. 3, pp. 250-258, Mar. 2008.

[15] S. Honda, Y.-G. Baek, T. Ikuno, H. Kohara, M. Katayama, K. Oura, and T. Hirao, "SiC nanofibers grown by high power microwave plasma chemical vapor deposition," Appl. Surf. Sci., vol. 212-213, pp. 378-382, May 2003.

[16] M. Vennekamp, I. Bauer, M. Groh, E. Sperling, S. Ueberlein, M. Myndyk, G. Mäder, and S. Kaskel, "Formation of SiC nanoparticles in an atmospheric microwave plasma," Beilstein J. Nanotechnol., vol. 2, pp. 665-673, 2011.

[17] J. Knipping, H. Wiggers, B. Rellinghaus, P. Roth, D. Konjhodzic, and C. Meier, "Synthesis of High Purity Silicon Nanoparticles in a Low Pressure Microwave Reactor," J. Nanosci. Nanotechnol., vol. 4, no. 8, pp. 1039-1044, 2004.

[18] D. Vollath and D. V Szabo, "Synthesis of nanocrystalline MoS2 and WS2 in a microwave plasma," Mater. Lett., vol. 35, pp. 236-244, 1998.

[19] Y. Hattori, S. Nomura, S. Mukasa, H. Toyota, T. Inoue, and T. Kasahara, "Synthesis of tungsten trioxide nanoparticles by microwave plasma in liquid and analysis of physical properties," J. Alloys Compd., vol. 560, pp. 105-110, May 2013.

[20] A. Irzh, I. Genish, L. Klein, L. a Solovyov, and A. Gedanken, "Synthesis of ZnO and Zn nanoparticles in microwave plasma and their deposition on glass slides.," Langmuir, vol. 26, no. 8, pp. 5976-84, Apr. 2010.

[21] H. Sone, T. Kaneko, and N. Miyakawa, "In situ measurements and growth kinetics of silicon carbide chemical vapor deposition from methyltrichlorosilane," J. Cryst. Growth, vol. 219, no. 3, pp. 245-252, Oct. 2000.

[22] G. D. Papasouliotis and S. V. Sotirchos, "Experimental study of atmospheric pressure chemical vapor deposition of silicon carbide from methyltrichlorosilane," J. Mater. Res., vol. 14, no. 08, pp. 3397-3409, Jan. 2011.

[23] T. Kaneko, N. Miyakawa, H. Sone, and H. Yamazaki, "Growth kinetics of hydrogenated amorphous silicon carbide films by RF plasma-enhanced CVD using two kinds of source materials," Thin Solid Films, vol. 409, no. 1, pp. 74-77, Apr. 2002.

[24] X. Wang, K. Su, J. Deng, Y. Liu, Y. Wang, Q. Zeng, L. Cheng, and L. Zhang, "Initial decomposition of methyltrichlorosilane in the chemical vapor deposition of siliconcarbide," Comput. Theor. Chem., vol. 967, no. 2-3, pp. 265-272, Aug. 2011.

[25] D. Jaglin, J. Binner, B. Vaidhyanathan, C. Prentice, B. Shatwell, and D. Grant, "Microwave Heated Chemical Vapor Infiltration: Densification Mechanism of SiCf/SiC Composites," J. Am. Ceram. Soc., vol. 2717, p. 060613004617005-???, Jun. 2006. 
[26] L. Zhong and L. Hou, "Nano-Structured Si-C-N Composite Powder Produced by Radio Frequency Induction Plasma and its Microwave Absorbing Properties," J. Eng. Sci. Technol. Rev., vol. 6, no. 12, pp. 160-163, 2013.

[27] S. H. Mousavipour, V. Saheb, and S. Ramezani, "Kinetics and Mechanism of Pyrolysis of Methyltrichlorosilane †," J. Phys. Chem. A, vol. 108, no. 11, pp. 19461952, Mar. 2004.

[28] C. L. Yaws, Yaws' Critical Property Data for Chemical Engineers and Chemists. New York: Knovel, 2014.

[29] R. P. Cardoso, T. Belmonte, C. Noël, F. Kosior, and G. Henrion, "Filamentation in argon microwave plasma at atmospheric pressure," J. Appl. Phys., vol. 105, no. 9, 2009.

[30] P. Shukla and A. Mamun, Introduction to Dusty Plasma Physics. Cornwall: Institute of Physics Publishing, 2002.

[31] J. Cooper, "Plasma spectroscopy," Reports Prog. Phys., vol. 29, no. 1, p. 35, 1966.

[32] B. Layden, V. Cheung, and A. A. Samarian, "Effect of Dust Particle Growth on the Emission Spectrum of a Complex Plasma," IEEE Trans. Plasma Sci., vol. X, no. X, pp. 6-7, 2011.

[33] A. Kramida, Y. Ralchenko, J. Reader, and NIST ASD Team, "NIST Atomic Spectra Database (ver. 5.2)," 2014. [Online]. Available: http://physics.nist.gov/asd. [Accessed: 23-Oct-2014].

[34] K. Wagatsuma and K. Hirokawa, "Characterization of Atomic Emission Lines from Argon, Neon, and Nitrogen Glow Discharge Plasmas,” Anal. Chem., vol. 57, pp. 2901-2907, 1985.

[35] M. Milan and J. J. U. Laserna, "Diagnostics of silicon plasmas produced by visible nanosecond laser ablation," Spectrochim. Acta Part B At. Spectrosc., vol. 56, pp. 275288, 2001.

[36] L. Di, J.-R. Shi, S.-J. Wang, Q.-L. Dong, J. Zhao, Y.-T. Li, J. Fu, F.-D. Wang, Y.-J. Shi, B.-N. Wan, G. Zhao, and J. Zhang, "Emission Lines of Boron, Carbon, Oxygen and Iron in Tokamak Plasma," Chinese Phys. Lett., vol. 28, no. 7, p. 075201, Jul. 2011.

[37] J. Deng, K. Su, X. Wang, Q. Zeng, L. Cheng, Y. Xu, and L. Zhang, "Thermodynamics of the gas-phase reactions in chemical vapor deposition of silicon carbide with methyltrichlorosilane precursor," Theor Chem Acc., vol. 122, pp. 1-22, 2009.

[38] B. Trusov, "Terra - Phase and Chemical Equilibrium of Multicomponent Systems." Bauman Moscow State Technical University, Moscow, 2006.

[39] C. Tendero, C. Tixier, P. Tristant, J. Desmaison, and P. Leprince, "Atmospheric pressure plasmas: A review," Spectrochim. Acta Part B At. Spectrosc., vol. 61, no. 1, pp. 2-30, Jan. 2006. 
